\title{
The Relationship Between Reserve Items and Exchange Rate in Malaysia: Evidence from Non-linear Model
}

Seyed Alireza Seyed Ahmadian, Rosita bt. Hamdan, Jerome Kueh Swee Hui To Link this Article: http://dx.doi.org/10.6007/IJARBSS/v11-i11/11178 DOI:10.6007/IJARBSS/v11-i11/11178

Received: 10 September 2021, Revised: 05 October 2021, Accepted: 24 October 2021

Published Online: 06 November 2021

In-Text Citation: (Ahmadian et al., 2021)

To Cite this Article: Ahmadian, S. A. S., Hamdan, R. bt., \& Hui, J. K. S. (2021). The Relationship Between Reserve Items and Exchange Rate in Malaysia: Evidence from Non-linear Model. International Journal of Academic Research in Business and Social Sciences, 11(11), 245 - 261.

Copyright: @ 2021 The Author(s)

Published by Human Resource Management Academic Research Society (www.hrmars.com) This article is published under the Creative Commons Attribution (CC BY 4.0) license. Anyone may reproduce, distribute, translate and create derivative works of this article (for both commercial and non-commercial purposes), subject to full attribution to the original publication and authors. The full terms of this license may be seen at: http://creativecommons.org/licences/by/4.0/legalcode

Vol. 11, No. 11, 2021, Pg. $245-261$

Full Terms \& Conditions of access and use can be found at http://hrmars.com/index.php/pages/detail/publication-ethics 


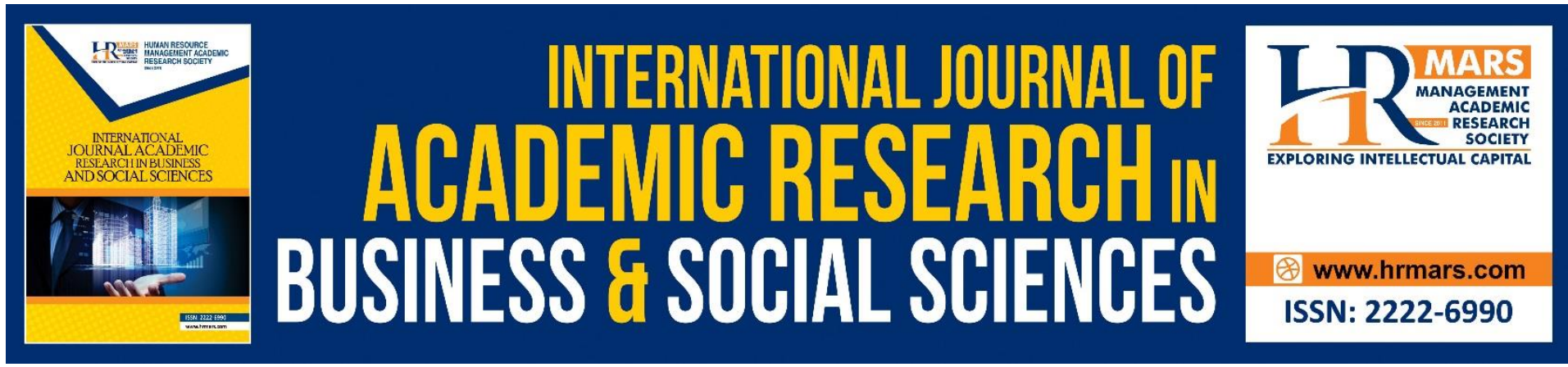

\title{
The Relationship Between Reserve Items and Exchange Rate in Malaysia: Evidence from Non- linear Model
}

\author{
Seyed Alireza Seyed Ahmadian, Rosita bt. Hamdan, Jerome \\ Kueh Swee Hui \\ Faculty of Economics and Business, University Malaysia Sarawak, 94300, Kuching, Malaysia \\ Email: alirezaseyedahmadian2@gmail.com
}

\begin{abstract}
The objectives of this study are first, to examine a nonlinear long-run relationship between exchange rate and reserve and related item in Malaysia. Second, to examine the causal relationship between exchange rate, reserve and related item, money supply, interest rate, foreign direct investment, and price in Malaysia. Third, to forecast the relationship between exchange rate, reserve and related item, money supply, interest rate, foreign direct investment, and price in Malaysia for the next 50 years. To achieve our objective, we employed the nonlinear autoregressive distributed lag model (NARDL), Toda Yamamoto causality test and variance decomposition. We utilize a time series dataset from 1982 to 2018. We find reserve items are significant to have a negative relationship with exchange rate. However, it limits to only a decrease in reserve items will encourage the Ringgit to be depreciated. On the other hand, reserve items are expected to influence more in exchange rate fluctuation in the next 50 years. On the other hand, reserve items are significant to cause FDI inflow in Malaysia.
\end{abstract}

Keyword: Non-linear Model, Exchange rate, Reserve Items

\section{Introduction}

Malaysia is a small open economy. Malaysia is experiencing the openness index that is more than one. According to the statistics that publish in Worldbank development indicator (WDI), the value of openness index of Malaysia in 2018 was recorded at 1.31. Meaning to say here, Malaysian economy is an open economy, and their international trade are valued more than domestic production. In other words, Malaysian economy is highly dependent on global market and their export activities are driving towards their economic growth. Therefore, an internal and external sector are important to support their international trade activities, consequently, it can contribute to a rapid economic growth in the future. In 2018, the share of import was about $61.7 \%$ (of GDP), while the share of export was about $68.8 \%$ (of GDP). Tellingly, the share of import input content in Malaysia is very high. It is approximately about $58 \%$ of total import is accounted in the year 2017. 
With this kind of nature, exchange rate stability plays a vital role in a small economy with higher volume of international trade in the economy like Malaysia (Husaini et al., 2019). It determines the real cost/revenue that an economy must commit/receive. Thus, currency appreciation and depreciation will translate to several impact on an economy. According to the hypothesis of Mundell-Fleming model, currency appreciation is significant to bring harm to export as it rises the price of export goods and encourages the demand for imported goods (Abeysinghe \& Yeok, 1998; Fisher \& Huh, 2002). However, this hypothesis is invalid if an economy has higher value of import input production in an economy. In this scenario, the currency appreciation will drive the cost of production up as the price of import input production becomes expensive. Hence, the price for final good becomes more expensive (Husaini et al., 2019).

Monetary policy regime plays a vital role in stabilizing the rate of nominal exchange rate. It is also expected to influence a direct and immediate impact on currency fluctuation. A small economy like Malaysia really depends on global economy in accumulating its national wealth. Favorable exchange rate will support the economy to boost and consequently it improves macroeconomics performance. Hence, it is crucial to identify how strong is the monetary tools in causing the value of local currency, which in this study we are concerning Malaysian Ringgit value in international money market. The capacity of reserve items is different as compared to other monetary tools such as interest rate, money supply and etc. It is more productive tools for a government to influence Ringgit fluctuation in international money market because the currency exchange is resolved because of economic situations in coasting rate of exchange system. In such manner, unnecessary changes in currency could be happened because of abundance interest or diminishing in rate of exchange gracefully. On account of unnecessary unpredictability in currency, BNM could oversee floating rate of exchange to support price constancy.

Hence, this study is intended to explore the asymmetric impact of reserve items on exchange rate in Malaysia. Many studied ignore the role of reserve and related in examining the factor that determine exchange rate fluctuation (Abdul-Rahaman \& Yao, 2019). It is important to identify the magnitude influence of reserve on exchange rate as the reserve is one of the monetary tools that the policymaker will use to monitor the value of currency is always reasonable in the money market. An economy that applies a managed-floating exchange rate like Malaysia need a wide coverage of reserve and related item to ensure the exchange rate is in favorable to drive sustainable economic growth.

The objectives of this study are first, to examine a nonlinear long-run relationship between exchange rate and reserve and related item in Malaysia. Second, to examine the causal relationship between exchange rate, reserve and related item, money supply, interest rate, foreign direct investment, and price in Malaysia. Third, to forecast the relationship between exchange rate, reserve and related item, money supply, interest rate, foreign direct investment, and price in Malaysia for the next 50 years.

The contribution of this study is to extend the finding in the form of nonlinear estimation in exploring the relationship between exchange rate and reserve (Reserves and related itemsBalance of Payment). Thus, a Nonlinear Autoregressive Distributed Lag Model (NARDL) is employed in this study. According to Shin et al (2014), NARDL able to read the asymmetric 
impact of an exogenous variable to the endogenous variable. It may give wider information as it offers a two-dimension impact of exogenous factor (Sek, 2017; Ibrahim, 2015; Lacheheb and Sirag, 2019). Thus, we can capture the significance of a decrease and increase of reserve and related item on a change in exchange rate. Unlike (Martinez, 1999; Seghezza et al., 2017), their finding just limits to linear assumption in exploring the relationship between exchange rata and reserve and related items. A perfect linear assumption is not working in all situation (Sarmadi et al., 2014).

The structure of this paper is as follow. Next section is to review related literature. Section 3 will discuss about our model specification. Section 4 and 5 will describe the econometric technique and the data. Chapter 6 and 7 will explain the finding and empirical discussion. Section 8 is for conclusion and policy implication.

\section{Literature Review}

In early literature, Vuravlivker (1987); Macdonald (1987) had emphasized the important of reserve item in managing floating exchange rate. Vuravlivker (1987) figureout the significant of reserve items in managing floating exchange rate of Argentina. While Macdonald (1987) was constructed the suitable econometric model in expressing the importance of reserve items in influencing a change in exchange rate.

Flood et al (1998) investigates the relationship between reserves and exchange rate in 12 Latin American countries namely Argentina, Bolivia, Chile, Costa Rica, Dominican Republic, Mexico, Paraguay, Peru, Uruguay, Brasil, Equador, and El Salvador. This Study uses a quarter data from 1970 to 1989 . This study concludes the reserves is interacted with exchange rate fluctuation.

Up to an advance econometric analysis, Kasman and Ayhan (2008) investigate the relationship between reserves and exchange rate in Turkey by using structural breaks, unit roots and cointegration approaches. This study uses monthly data from 1982 to 2005 . The finding indicates that both reserves and exchange rate is cointegrated in the long run. In addition, there is a causal relationship that runs from reserves to exchange rate. Aizenman et al (2012) also concludes that reserves are more effective than other monetary tools and fiscal tools in managing floating exchange rate. This study uses Latin American countries as the sample of study. Basu (2012) added even though reserves are effective to interfere the money market, but it is advised for the central bank to plan and schedule the activity to buy and to sell the currency by using reserves item to avoid an undervalue of a currency gives negative impact to the economy. Aytug (2017) investigates the role of reserves item in influencing exchange rate in 14 emerging countries namely Argentina, Brazil, Chile Colombia, Czech Republic, Hungary, India, Indonesia, Mexico, Poland, Romania, Russia South Africa, and Turkey. This study use a monthly data from 2001-2014. This study concludes that reserve items are working efficiently in influencing exchange rate fluctuation in all sample countries.

Seghezza et al (2017) reviews China has started to increase its reserves items after Asian financial crisis $1997 / 1998$. This study stresses that it is important to have a huge capacity of reserve items to prevent the money market efficiently. Different with other study, this study explores the determinant of reserve items in China. This study suggests a factor of trade 
openness, exchange rate and democracy index play a significant role in accumulating more reserve items.

All studies as mention above used linear estimation model. Sometime, linear estimation in the real world (Pal and Mitra, 2019). Hence, we fill the gap in the current literature by employing a non-linear approach in exploring the asymmetric impact or reserve items on exchange rate in Malaysia.

\section{Model}

To examine the relationship between exchange rate, money supply, interest rate, consumer price index, foreign direct investment and reserve in Malaysia, the functional form of the model is as below:

$$
(\mathrm{ER})_{\mathrm{t}}=\beta_{0}+\beta_{1}(\mathrm{RV})_{\mathrm{t}}+\beta_{2}(\mathrm{IR})_{\mathrm{t}}+\beta_{3}(\mathrm{P})_{\mathrm{t}}+\beta_{4}(\mathrm{FDI})_{\mathrm{t}}+\beta_{5}(\mathrm{M} 2)_{\mathrm{t}}+\varepsilon_{t}
$$

Where,

$(\mathrm{ER})_{\mathrm{t}}=$ Exchange rate $(\mathrm{RM} / \mathrm{USD})$

$(\mathrm{RV})_{\mathrm{t}}=$ Reserves and related items (Balance of Payment) constant at 2010 in RM

$(\mathrm{M} 2)_{\mathrm{t}}=$ Money supply

$(\mathrm{IR})_{\mathrm{t}}=$ Lending Interest Rate

$(\mathrm{P})_{\mathrm{t}}=$ Consumer Price Index constant at 2010

$(F D I G)_{t}=$ Net inflow of Foreign Direct Investment constant at 2010 in RM

$\beta_{0}=$ Constant term

$\beta_{1}, \beta_{2}, \ldots, \beta_{5}=$ coefficient of independent variables

$\varepsilon_{t}=$ error term at period of time

LM2, LIR, LP, LFDI and LRV are chosen as our exogenous variable respect to the monetarist point of view. According to the monetarist viewpoint, the money supply is expected to have a positive relationship with an exchange rate. The higher the money supply the higher the exchange rate. A surplus of Ringgit in money market will consequently lead to currency depreciation. Multiples studies had employed money supply as an exogenous variable in exploring the factor to cause exchange rate fluctuation (Onis \& Ozmucur, 1990). Figure 3.1 is illustrated to show how the money supply causes Ringgit to depreciate, theoretically. Some studies use M2 as an independent variable are (Husaini et al., 2019; Adusei \& Gyapong, 2017).

Interest rate is the price of borrowing. It is a basic indicator to determine the rate of return in monetary investment. The higher the interest rate, the higher the rate of return (Adusei \& Gyapong, 2017). Thus, higher interest rate will attract the investor to hold Ringgit in his account. Theoretically, interest rate has a negative relationship with exchange rate (Mankiw, 2017; Adusei \& Gyapong, 2017).

Consumer price index refer to a price level of a bucket of normal good in an economy (Mankiw, 2017). CPI is closely related to the cost of living in an economy. The higher the cost of living, the more discourage the people to hold ringgit. Theoretically, CPI has a positive relationship with exchange rate (Ha et al., 2020; Adusei \& Gyapong, 2017). 
FDI refers to the amount of investment that come from abroad to be invested in home country. Larger FDI inflows in home country will encourage foreign investor to hold home currency. Thus, the higher the volume of FDI inflows in Malaysia, the more appreciate the Ringgit will be. Theoretically, FDI has a positive relationship with exchange rate.

\section{Methodology}

In this study, we employ the nonlinear autoregressive distributed lag model (NARDL) to account for the asymmetric relationship between LRV and LER, we follow Ibrahim (2015) and Lacheheb and Sirag (2019) to specify our empirical models as follows:

$$
L E R=\beta_{0}+\beta R Y^{\forall}+\beta_{2} R Y+\beta_{3} M R_{t}+\beta_{4} I R+\beta_{5} P_{t}+\beta_{6} F D_{t}+\varepsilon_{t}
$$

The asymmetric impact of LRV can be captured by adding the positive changes of oil price $\left(L R \nabla_{t}\right)$ and the negative changes of oil price $\left(L R \nabla_{t}\right)$. The $L R \nabla_{t}$ and $L R V_{t}$ are a function of partial sums of the positive and negative changes in OP respectively.

We formulate $L R \nabla_{t}$ and $L R \nabla_{t}$ as follows:

$$
\begin{aligned}
& L R \forall=\sum_{t=1}^{+} N R \forall=\sum_{t=1}^{+} \max (R, W) \\
& L R \forall=\sum_{t=1}^{+} N R \forall=\sum_{t=1}^{+} \min (R, W)
\end{aligned}
$$

$\beta_{1}$ is the long run parameter of $L R \nabla_{t}$ and $\beta 2$ is the long run parameter of $L R V_{t}$. If $\beta_{1}$ is positive, it is interpreted that $L R \nabla_{t}$ have a positive relationship with the endogenous variable and vice versa. However, if $\beta_{2}$ is positive, we interpret $L R V_{t}$ in an adverse manner whereby $L R V_{t}$ has negative relationship with endogenous variable ${ }^{1}$. While $\beta_{3}, \beta_{4}, \beta_{5}$ and $\beta_{6}$ are the long run linear parameters for LM2, LIR, LP, and LFDI, respectively.

To adapt the nonlinear autoregressive distributed lag model (NARDL), we rewrite equations $(X)$ in an unrestricted error correction form as proposed by Pesaran et al (2001) and Shin et al. (2014) as follows:

$$
\begin{aligned}
& \Delta E R=\alpha_{1}+\sum_{i=1}^{\infty} \delta_{i} \Delta C L E_{t} R+\sum_{j=0}^{\infty} \Omega_{i} L R V_{t-j}+\sum_{k=0} \gamma_{k} N R V_{t-k}+\sum_{=0}^{\infty} \rho N M_{t-l}+\sum_{m=0}^{\infty} \lambda_{n} N I R_{t}+ \\
& \sum_{n=0} \eta_{h} \Delta_{t-v}+\sum_{p=0} \tau_{p} \Delta F D_{t} I_{p}+\pi_{1} L E R_{1}+\pi_{2} L R V_{t-1}+\pi_{3} L R V_{t-1}+\pi_{4} L M R_{t-1}+\pi_{5} L R_{t 1} \\
& +\pi_{\delta} L P_{t-1}+\pi \xi L D L_{1}+\varepsilon_{t}
\end{aligned}
$$

${ }^{2}$ The long-run symmetry can be tested using a Wald test of the null hypothesis: $\pi^{+} 2=\pi^{-3}$. The positive and negative long-run coefficients of LRV can then be calculated as $\beta^{+} L R V^{+}=\pi^{+} 2 /-$ $\pi 1, \beta^{-} L^{-} V^{-}=\pi^{+} 3 /-\pi 1$. The short-run adjustment to a positive and a negative shock of LRV is taken by the parameters $\Omega^{+} i$ and $\gamma^{-} k$, respectively. The short-run symmetry can equally be tested by using a standard Wald test of the null hypothesis: $\Omega^{+} i=\gamma^{-} k$.

\footnotetext{
${ }^{1}$ For further explanation, please refer to Ibrahim (2015) and Lacheheb and Sirag (2019).

${ }^{2}$ For further explanation, please refer to Atil et al. (2014).
} 
F-statistic for the bound test is used to determine the existence of long-run relationship in the model (Pesaran et al., 2001; Shin et al., 2014). The null hypothesis is no cointegration in the model. Three outcomes can be counted: 1) we have enough evidence to reject the null hypothesis if the value of F-statistic exceeds the upper critical bounds. 2) We do not have enough evidence to reject the null hypothesis if the value of F-statistic below the respective lower critical bounds. 3) The result is inconclusive if the value of F-statistic is in between the value of upper critical bound and lower critical bound.

\section{Data}

The annually time series data for the period over 1982 to 2018 has been taken to achieve the objectives of the study. A series data for exchange rate, reserve, money supply, lending interest rate, CPI and FDI are retrieved from Worldbank database (2019). The plot for each series that employed in the model is illustrated in Figure 1. The plot of LER, LFDI, LM2, LP and LRV are in upward trend. While the plot of LIR is in downward trend. 
LER

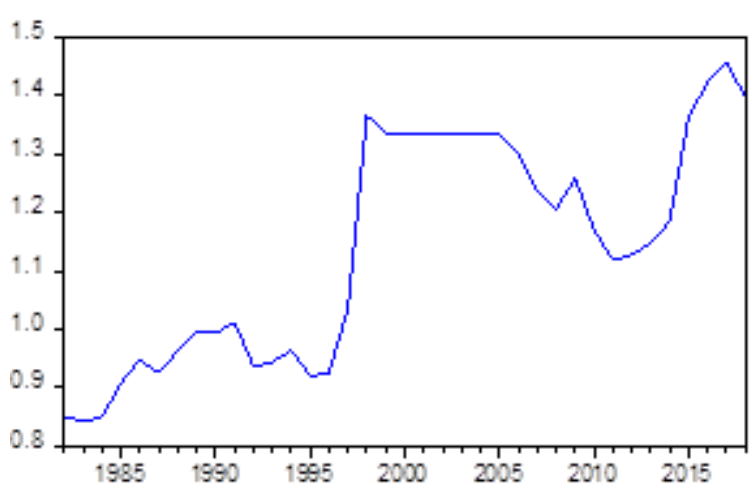

LLM2

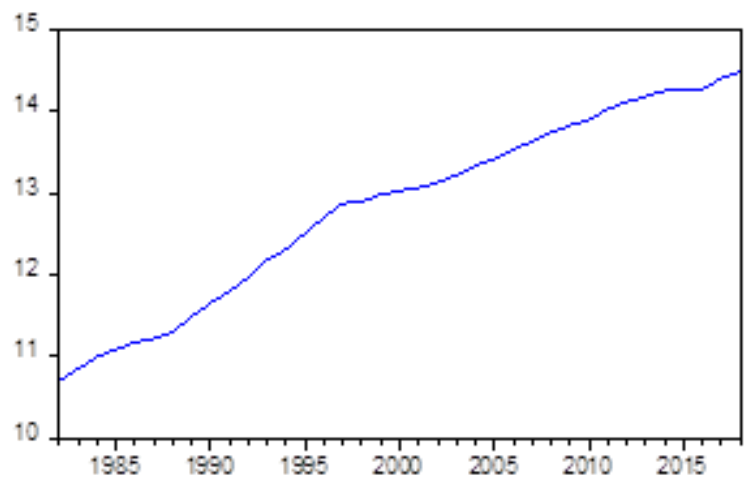

LP

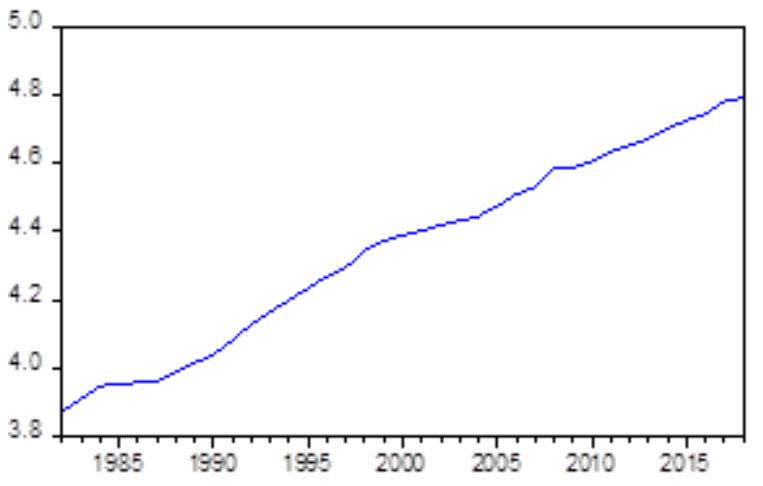

LFDI

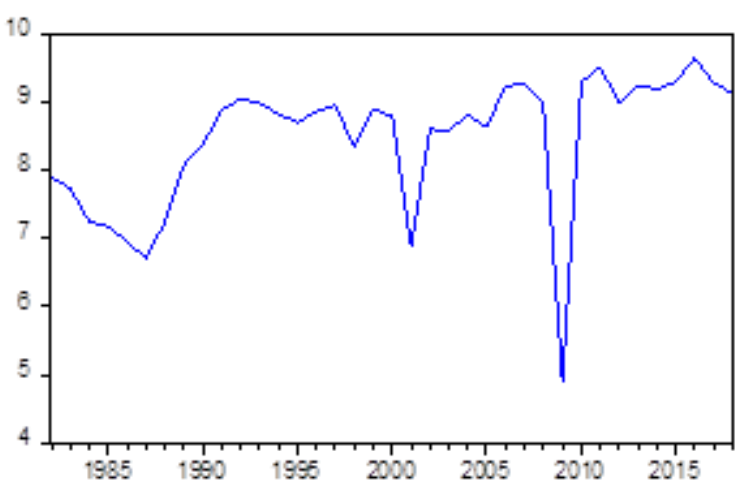

LIR

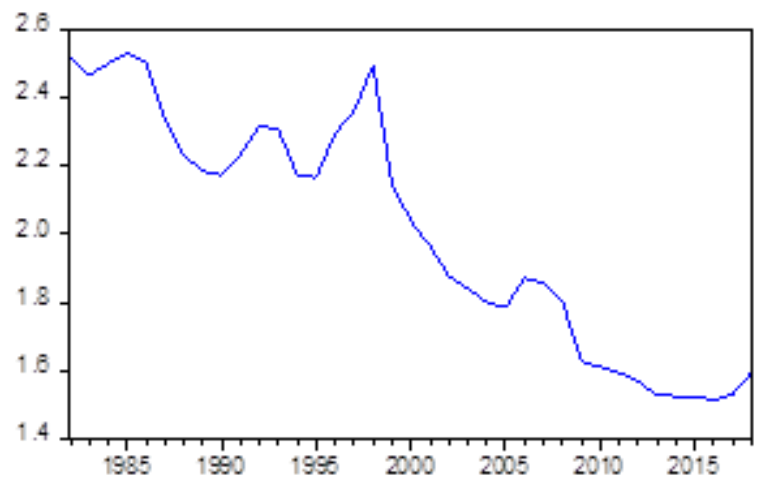

LRV

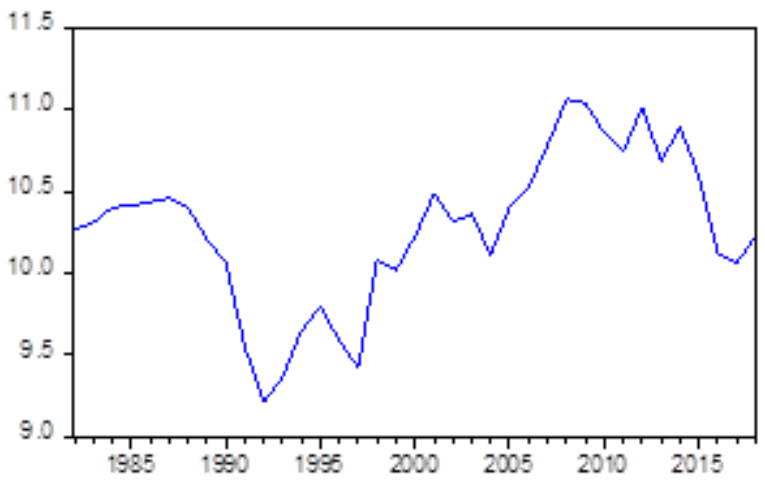

Figure 1:The Plot OF Series

\section{Empirical Result}

Phillips-Perron Unit Root Test

First of all, we presented the result for unit root test. The result for unit root test for PhillipPerron (PP) test is presented in table 2. PP unit root tests concludes that all series are stationary at first different except LFDI. We proceed to cointegration test by employing Autoregressive Distributed Lag (ARDL) cointegration test. It is because ARDL model allow a mix of series stationary at level and at first different as long as a series to be employed as endogenous variable is stationary at first different. 
Table 1: Phillips-Perron Unit Root Test

\begin{tabular}{|c|c|c|c|c|}
\hline \multirow[t]{2}{*}{ Variable } & \multicolumn{2}{|c|}{$I(0)$} & \multicolumn{2}{|c|}{ I(1) } \\
\hline & Constant & Trend & Constant & Trend \\
\hline LER & -1.3529 & -1.8827 & $-4.547 * * *$ & $-4.4637 * * *$ \\
\hline LIR & -0.916 & -2.2659 & $-4.9441 * * *$ & $-4.7776 * * *$ \\
\hline LP & -0.6644 & -1.7348 & $-4.7383 * * *$ & $-4.6902 * * *$ \\
\hline LFDI & $-3.9881 * * *$ & $-4.9559 * * *$ & $-20.1463 * * *$ & $-19.7007 * * *$ \\
\hline LM2 & -2.188 & -0.8415 & $-3.4219 * *$ & $-3.7691 * *$ \\
\hline LRV & -1.6535 & -1.8007 & $-5.305 * * *$ & $-5.2183 * * *$ \\
\hline
\end{tabular}

Bounds Test

We employ the bounds test to identify either our model is significantly cointegrated or not cointegrated in the long run. Table 2 is reported the result of bounds test. The F-statistics has confirmed that our model is significantly cointegrated in the long run. It is significant at $5 \%$ significant value. According to the AIC criteria, the best lags to be chose is 1,0,4,0,2,3.

Table 2: Bounds Test

\begin{tabular}{lll}
\hline Model & $1,0,4,0,2,3$ & \\
\hline F-Test & $3.4676^{* *}$ & \\
\hline Critical Value & & 11 \\
\hline $10 \%$ & 10 & 3 \\
\hline $5 \%$ & 2.08 & 3.38 \\
\hline $1 \%$ & 2.39 & 4.15 \\
\hline
\end{tabular}

Note: ${ }^{* * *},{ }^{* *}$ and ${ }^{*}$ denote significance at the $1 \%, 5 \%$ and $10 \%$ significance levels respectively

\section{Long Run Coefficient}

Once we confirm our model is cointegrated in the long run, we proceed to estimate the long run coefficient. The long run coefficient result is presented in table 3 . In general, LFDI, LRV and LP were found to be significant at $5 \%$ critical value with negative sign. While LM2 was significant to cause LER at $5 \%$ critical value with positive sign. All in all, the magnitude impact of LP was expected to give the greatest impact to cause LER. We have not enough evident to prove the LIR was significant to cause LER. For comparison purpose, we estimate our long run coefficient by employing FMOLS and DOLS. As reported in table 4, the result for both FMOLS and DOLS are consistent with our ARDL long run estimation.

We extend our finding to explore the asymmetric relationships between LRV and endogenous variable. The NARDL is employed to estimate a non-linear coefficient. According to the AIC criteria, the best lags to be chose is $1,0,0,1,0,0,1$. It is reported in Table 3 . A non-linear estimation for the coefficient of LRV indicates that the asymmetric impact of LRV on LER is incomplete. There is only a decrease of LRV (LRV-) is expected to influence a change on LER. A $1 \%$ increase in LRV is expected to decrease LER about $0.34 \%$ while other variables are constant. The magnitude changes of LRV- is bigger than the magnitude change of LRV in linear model. An increase in LRV (LRV) is expected not to affect any changes on LER. Since NARDL model is more informative than ARDL model, we conclude that the LRV is just only caused to a change in LER when the LRV is increased. 
The rest control variables are found to be consistent with the result of linear estimation (ARDL). However, the degree of magnitude for all variables are varied. According to the ceteris paribus assumption, the interpretation of all control variables is as follow:

- $1 \%$ increase in LP will lead to $2.33 \%$ decreases in LER while holding all variables are constant.

- $1 \%$ increase in LM2 will lead to $0.49 \%$ increases in LER while holding all variables are constant.

- $1 \%$ increase in LFDI will lead to $0.09 \%$ decreases in LER while holding all variables are constant.

ECT coefficient also can be used to indicate either the model is cointegrated or not cointegrated in the long run. The result of ECT is presented in Table 3. The coefficient of ECT is found significant at $1 \%$ critical value. -0.5669 inform us that our model needs approximately half years to fully transferred to explain our endogenous variables. This result also supports the bound test which suggest our model is integrated in the long run.

Table 3: Long Run Coefficient

\begin{tabular}{lll}
\hline Variable & ARDL & NARDL \\
\hline Model & $1,0,4,0,2,3$ & $1,0,0,1,0,0,1$ \\
\hline LRV & $-0.0628^{* *}$ & - \\
\hline LRV+ & - & 0.0258 \\
\hline LRV- & - & $-0.3387^{* * *}$ \\
\hline LM2 & $1.0255^{* *}$ & $0.48696^{* *}$ \\
\hline LFDI & $-0.1072^{*}$ & $-0.0945^{* * *}$ \\
\hline LP & $-3.5347^{* *}$ & $-2.3326^{* * *}$ \\
\hline LIR & 0.3478 & $0.4973^{* *}$ \\
\hline ECT & $-0.5669^{* * *}$ & - \\
\hline Diagnostic Test & & \\
\hline J-B Test & 0.4515 & 0.3822 \\
\hline Breusch-Godfrey Serial & 2.5123 & 0.2086 \\
Correlation LM Test & & \\
\hline ARCH & 0.1501 & 1.9349 \\
\hline Ramsey Test & 1.3503 & 0.4549 \\
\hline
\end{tabular}

Note: ${ }^{* * *},{ }^{* *}$ and ${ }^{*}$ denote significance at the $1 \%, 5 \%$ and $10 \%$ significance levels respectively

All diagnostic test i.e J-B Test, Breusch-Godfrey, Serial Correlation LM Test, ARCH, and Ramsey Test indicate that our ARDL model is in good fit. Figure 2 and 3 illustrate the result of CUSUM and CUSUM square, respectively. Both of these figures show that our model is stable. Thus, the result of diagnostic tests reported in Table 3 and CUSUM and CUSUM square confirm that our model is in good fit. 


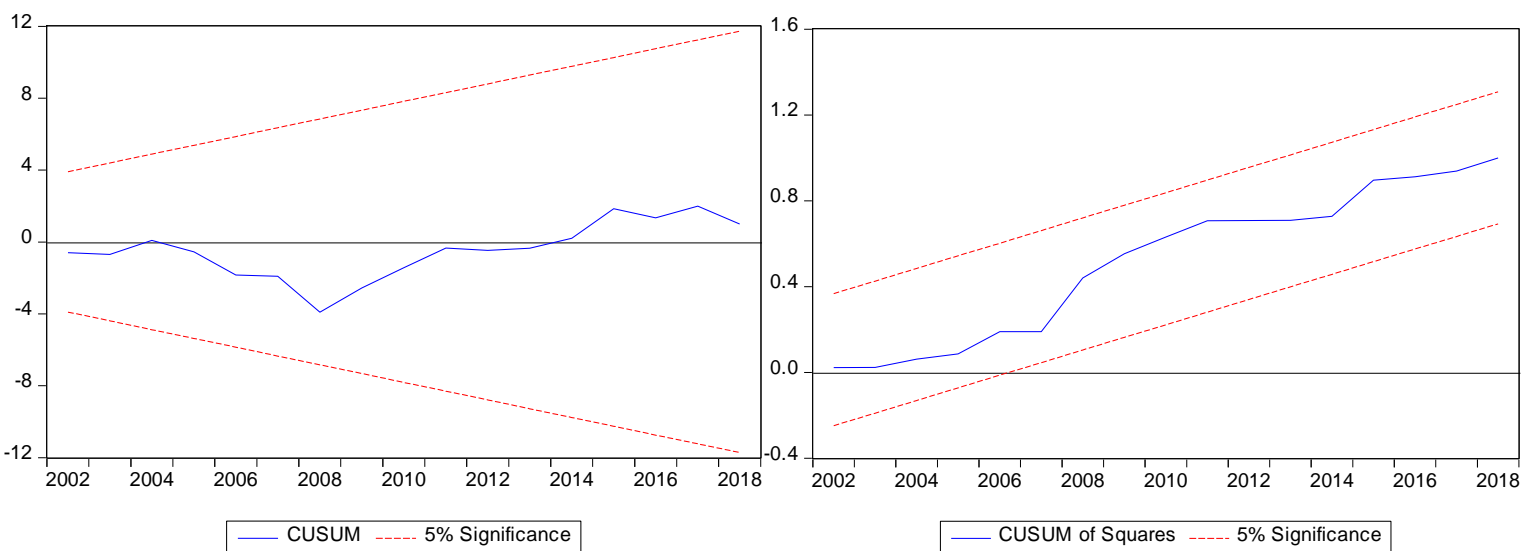

Figure 2: CUSUM and CUSUM Square (ARDL)

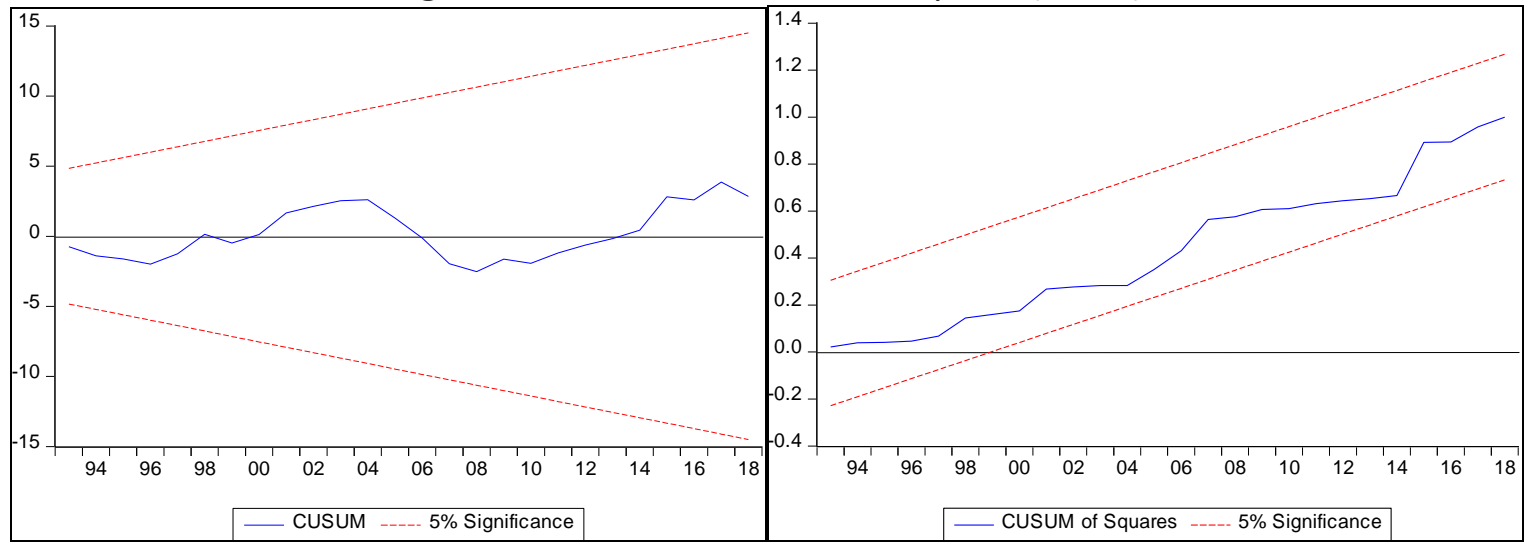

Figure 3: CUSUM and CUSUM Square (NARDL)

Toda-Yamamoto Causality Test

To dig more information on the relationship between our endogenous variable and exogenous variables, we employ Toda-Yamamota causality test. This test allows us to discover other possible directional relationship existed in our model.

Table 4: Toda-Yamamoto Causality

\begin{tabular}{lllllll}
$\begin{array}{llllll}\text { Exogenous } \\
\text { Variable }\end{array}$ & \multicolumn{6}{l}{ Endogenous Variables } \\
\cline { 2 - 7 } & LER & LFDI & LM2 & LRV & LP & LIR \\
\hline LER & - & 0.743 & 0.357 & 0.4299 & 0.0198 & 0.4793 \\
\hline LFDI2 & 0.0311 & - & 0.6989 & 0.3567 & 0.0085 & 0.1273 \\
\hline LM2 & 0.0003 & $3.6899^{*}$ & - & 0.0237 & 2.352 & $4.7572^{* *}$ \\
\hline LRV & 0.6878 & $4.1472^{* *}$ & 1.535 & - & 1.1067 & $4.3759^{* *}$ \\
\hline LP & $3.9326^{* *}$ & 3.5469 & 1.5975 & 0.499 & - & 0.9858 \\
\hline LIR & $3.7953^{*}$ & 2.3027 & $4.1143^{* *}$ & $3.796^{* *}$ & 0.824 & -
\end{tabular}

Note: ${ }^{* * *},{ }^{* *}$ and $*$ denote significance at the $1 \%, 5 \%$ and $10 \%$ significance levels respectively.

Table 4 reports the result for Toda-Yamamoto causality test. We found 2 bi-directional relationships. Those are as follow:

- A bi-directional between LM2 and LIR

- A bi-directional between LRV and LIR 
We also found 4 unidirectional relationship in our model. Those are as follow:

- A unidirectional relationship runs from LP to LER

- A unidirectional relationship runs from LIR to LER

- A unidirectional relationship runs from LM2 to LFDI

\section{Variance Decomposition}

For the purpose of competency, we just report the result of variance decomposition of LFDI, LM2, LRV, LP and LIR as the exogenous variable. It is reported in table 5.

Table 5: Variance Decomposition

\begin{tabular}{lllllll}
\hline \multicolumn{6}{l}{ Variance Decomposition of LER: } \\
\hline Period & LER & LFDI & LM2 & LRV & LP & LIR \\
\hline $\mathbf{1}$ & 100.0000 & 0.0000 & 0.0000 & 0.0000 & 0.0000 & 0.0000 \\
\hline $\mathbf{1 0}$ & 35.5881 & 5.2501 & 29.1186 & 15.7329 & 12.6289 & 1.6811 \\
\hline $\mathbf{2 0}$ & 28.1551 & 7.9981 & 27.907 & 18.0881 & 15.7524 & 2.0993 \\
\hline $\mathbf{3 0}$ & 26.5633 & 9.9698 & 22.7401 & 20.6254 & 18.0062 & 2.0951 \\
\hline $\mathbf{4 0}$ & 26.3528 & 11.5821 & 17.11 & 23.1128 & 19.8478 & 1.9942 \\
\hline $\mathbf{5 0}$ & 26.6677 & 12.7834 & 12.2066 & 25.2512 & 21.2154 & 1.8755 \\
\hline
\end{tabular}

For the next 50 years, LRV is expected to influence LER the most. LRV is forecasted to be able to explain LER about $25 \%$. In current, we found LP is giving greater impact on LER. This pattern is expected to change for next 50 years.

\section{Discussion}

The main finding of our result is first, price is expected to give greater impact on exchange rate rather than other exogenous variables. It means, the equilibrium point of exchange rate is very elastic to a change in the price level in Malaysia. In other word, the demand and the supply of Ringgit is sensitive on a status of living cost in Malaysia. This scenario is clearly explained in the economic theory. Theoretically, the value of cash in the pocket depends much on the price level. The higher the price level, the lower the value of cash in the pocket. The lower the value of cash in the pocket, the less desire the people to demand one particular currency. Thus, the utility or people's satisfaction to hold Ringgit is high if the price level (the cost of living) is low. Our econometric result is also supported by (Lee and Kim, 2018; Junttila and Korhonen, 2012; Berganza and Broto, 2012).

Second, the amount of reserve and related items is expected to have a negative relationship with exchange rate. This finding is also supported by (Abdul-Rahaman and Yao, 2019; Seghezza et. al., 2017; Flood et. al., 1998). However, we extend the current finding in the literature to offer a non-linear assumption. Statistically, reserve and related items will influence the exchange rate if only the reserve and related item is decreased. An increase in reserve and related items is expected not to improve the value of Ringgit. Theoretically, reserve and related items represent the capacity of a government to have a direct intervention on foreign exchange rate market in order to stabilize national currency. The higher the reserve and related items, the greater the capacity of a government to intervene the foreign exchange market to push the currency to be appreciated (Seghezza et. al., 2017; Flood et. al., 1998). However, our nonlinear estimation has confirmed that greater reserve and related items are not giving any contribution to improve Ringgit to be appreciated. In fact, a small reserve and related items capacity is expected to drive Ringgit to be depreciated. Even 
though greater reserve and related items give no meaning to Ringgit appreciation, it does not mean the policymaker need to put a side any strategy to strengthen the status of reserve and related account in national account. It is because, less capacity of reserve and related items will bring harm to Ringgit appreciation. A small country with high import input content like Malaysia really needs its currency to be appreciated in order to control the cost of living of a society (Husaini et. al., 2019). In this case, Malaysia there are other factors significant factor such as the level of productivity, infrastructure development, the level of education quality and ect that the policymaker to focus more as an effort to drive Ringgit to appreciate in the long run.

Third, we found the net FDI inflow is expected to have a negative relationship with exchange rate. This result is supported by (Kiyota and Urata, 2004). The higher the FDI inflow gains by the host country, the more the currency of a host country to be appreciated. FDI inflow will consequently increase the demand to hold the currency of a host country (Kiyota and Urata, 2004; Kosteletou and Liargovas, 2000). Technically, the investment that brings by the foreigner to host country (Malaysia) should be in local currency unit (Ringgit). In this channel, the demand on local currency unit (Ringgit) is directly increased. This will continuously happen throughout the period of the business (FDI) is operated in the host country.

Forth, we found the money supply is significant to have a positive relationship with exchange rate. This result is supported by (Kamin and Roges, 2000; Cornell, 1982). It is in line with monetary theory where the more the money to be printed in an economy, the more the currency to be depreciated. It is responded to the surplus of money occurs in money market. Technically, this surplus lead to depreciation as it forces by the market to normalize the equilibrium of exchange rate.

Fifth, we do not have enough evidence to prove the interest rate will influence exchange rate in the long run. This result is supported by (Kamin and Roges, 2000; Cornell, 1982). Theoretically, an interest rate just only giving its impact on exchange rate in the short run only (Mankiw, 2017).

\section{Conclusion and Policy Implication}

In summary, this study is exploring the impact of monetary policy and exchange rate in Malaysia. We have selected reserve items, interest rate and money supply as our indicator for monetary tools. We have chosen price level and FDI inflow as our control variable. Intriguingly, this research focuses more on the relationship between reserve items and the exchange rate, as reserve items have the potential to have a direct impact on the exchange rate equilibrium. To fill the gap in the current literature, we extend this study by examining the asymmetric impact of reserve items on exchange rate. To the best of our knowledge, this is the first study of asymmetric impact of reserve items on exchange rate conducted in Malaysia. This study was covered the period of 1982 to 2018. In accommodating this research sample, we had employed various time series empirical techniques. ARDL and NARDL were the main methodology we used in our research. ARDL was used to analyze our suggested model in concluding a linear estimation. ARDL was used to analyze our suggested model in concluding a non-linear estimation. To dig more empirical information, we also employed Toda Yamamoto causality test to discover any other possibility of causal relationship exist in our suggested model. To forecast the pattern of relationship of our suggested model in next 
50 years, we employed variance decomposition. Our major conclusion is that reserve items are important in causing negative exchange rates. The remaining variables have a substantial impact on the exchange rate in line with the economic theory.

These findings have significant policy bearings. To make our discussion clearer, we will list the main finding and it will follow by policy recommendation that based on that respected finding. First, our major finding offers reserve items are significant to have a negative relationship with exchange rate. However, it limits to only a decrease in reserve items will encourage the Ringgit to be depreciated. The higher the reserve items the more the Ringgit to be appreciated. An increase in reserve items are insignificant to cause a change in Ringgit fluctuation. It is suggested that the government change the reserve item threshold value over time as a monetary tool to keep the Ringgit from depreciating. When the business cycle is turning down, the value or reserve items should be enhanced. The Ringgit is projected to decline as the economy slows. To keep the Ringgit from depreciating any more, reserve items should be increased to curb the upward tendency in the exchange rate.

Second, FDI is significant to have a negative relationship with exchange rate. The higher the FDI inflow, the more the Ringgit to be appreciated. The lower the FDI inflow, the more the Ringgit to be depreciated. The existence of FDI in Malaysia will encourage the demand to hold Ringgit. Result, Ringgit becomes more valuable. To promote FDI inflow, it is recommended that the government increase the ease of doing business index by liberalizing as much bureaucracy as possible. This method is intended to boost Ringgit demand in the long run. The greater an economy's FDI influx, the higher the demand for Ringgit, particularly among international investors.

Third, CPI is significant to have a negative relationship with exchange rate. The higher the level of price the more the Ringgit to be appreciated. Revenue derives from price times quantity. The higher the price, the more revenue to be gained. The more revenue to be earned, the higher the return of an investment. Thus, it encourages the investor to hold Ringgit and invest in Malaysia. Reasonable inflation rate is drive to a health economic development as the incentive earn by all economic agents are quite competitive. Different with hyperinflation, it led to a situation of where the growth of income becomes meaningless as an increase of cost is too high. It also demolishes more consumer surplus. Hence, the welfare of the consumer is decreasing. Same with deflation, a decrease in price level will reduce the private revenue and consequently the rate of return of an investor. To stabilize the rate of inflation, it involves with multiple economic policies such as international trade policy, industrial master plan, entrepreneurship development policy and ect. These policies influence the aggregate demand and aggregate supply in an economy. Malaysia has three main economic master plans to ensure its economic condition is always in good health. Those are annual budget plan and a series of Malaysian plan. To ensure that these objectives are met, we suggest that the government strengthen its efficacy in implementing all of these measures. The government should concentrate on how to diversify aggregate demand and aggregate supply by reducing reliance on foreign sources. Domestic production should be bolstered in order for it to gain a larger proportion of aggregate demand and become the dominating force in an economy. Malaysia's economic security will be enhanced as a result of its dominance. As a result, maintain the pricing level throughout time. 
Forth, both monetary tools of interest rate and money supply are significant to cause exchange rate with positive sign. This result indicates that the monetary policy is giving a direct influence to Ringgit fluctuation. We believe that monetary policy should be strengthened. The ringgit is also a good monetary strategy for promoting economic growth. It also boosts the country's international competitiveness. For monetary recovery, the ability to undertake adjustment monetary policy with sufficient USD reserves and competitive interest rate regulation is recommended.

Fifth, reserve items are expected to have a unidirectional relationship with FDI inflow that runs from reserve items to FDI inflow. This result indicates that the level of reserve items in national account is one of the main factors to influence FDI inflow to grow in Malaysia. The government should clearly begin a strategic planning process for improving reserve goods. Communication to the public regarding connected items accounts is critical to ensuring that overseas investors are aware of the government's ability to limit Ringgit fluctuation. It is a part of the FDI inflow strategy. FDI inflow has a variety of effects on an economy's development. It also encourages people to value the Ringgit.

Sixth, our finding estimates that reserve items become the most influential exogenous variable in a change of exchange rate for the next 50 years. In current, price level has the highest magnitude impact to influence Ringgit to fluctuate. We suggest that the government develop a long-term strategy for increasing the value of reserve items. Higher reserve items will allow the government more power to act in the money market to keep the Ringgit fluctuating in a way that is always beneficial to Malaysia's economic development. Meanwhile, it is a good sign for an investor to trust in holding more Ringgit, as Ringgit is becoming less hazardous to hold due to a government's increased ability to affect the value of Ringgit.

\section{Reference}

Abdul-Rahaman, A., \& Yao, X. (2019). Reserves quantity and economic stability: the central bank of Ghana's position and practices. Heliyon. Doi:10.1016/j.heliyon.2019.e02856.

Abeysinghe, T., \& Yeok, T. L. (1998). Exchange rate appreciation and export competitiveness. The case of Singapore', Applied Economics, 30, $51-55$.

Adusei, M., \& Gyapong, E. Y. (2017). The impact of macroeconomic variables on exchange rate volatility in Ghana: The Partial Least Squares Structural Equation Modelling Approach. Research in International Business and Finance.

Aizenman, J., Edwards, J., \& Riera-Crichton, D. (2012). Adjustment patterns to commodity terms of trade shocks: The role of exchange rate and international reserves policies. Journal of International Money and Finance. 31; 1990-2016.

Akdogan, I. U. (2019). Understanding the dynamics of foreign reserve management: The central bank intervention policy and the exchange rate fundamentals. International Economics. doi.org/10.1016/j.inteco.2019.11.002.

Aytug, H. (2017). Does the reserve options mechanism really decrease exchange rate volatility? The synthetic control method approach. International Review of Economics and Finance. 51; 405-416.

Basu, K. (2012). How to devalue exchange rates, without building up reserves: Strategic theory for central banking. Economics Letters. 117; 758-761. 
Berganza, J. C., \& Broto, C. (2012). Flexible inflation targets, forex interventions and exchange rate volatility in emerging countries. Journal of International Money and Finance. 31; 428-444.

Cornell, B. (1982). Money supply announcement, interest rates and foreign exchange. Journal of International Money and Finance. 1; 201-208.

Değerli, A., \& Fendoğlu, S. (2015). Reserve option mechanism as a stabilizing policy tool: Evidence from exchange rate expectations. International Review of Economics and Finance. 35; 166-179.

Fisher, L. A., \& Huh, H. (2002) 'Real exchange rates, trade balances and nominal shocks: evidence for the g-7', Journal of International Money and Finance, 21, 497- 518.

Flood, R., Perraudin, W., \& Vitale, P. (1998). Reserve and exchange rate cycles. Journal of International Economics. 46; 31-59.

Ha, J., Stocker, M. M., \& Yilmazkuday, H. (2020). Inflation and Exchange Rate Pass-Through. Journal of International Money and Finance.

Husaini, D. H., Mansor, S. A, Karim, B. A, Puah, C. H. Kueh, J., \& Lau, E. (2019). Industrial Development, Subsidy Reform and Export Behaviour: An Evidence fromASEAN-5 Economies. Int. Journal of Economics and Management. 13; 51-61.

Ibrahim, M. H. (2015). Oil price and food price in Malaysia: a nonlinear ARDL analysis. Agricultural and Food Economics. 3, 1- 14.

Junttila, J., \& Korhonen, M. (2012). The role of inflation regime in the exchange rate passthrough to import prices. International Review of Economics and Finance, 24, 88 - 96.

Kasman, A., \& Ayhan, D. (2008). Foreign exchange reserves and exchange rates in Turkey: Structural breaks, unit roots and cointegration. Economic Modelling. 25; 83-92.

Kosteletou, N., \& Liargovas, P. (2000). Foreign direct investment and real exchange rate interlinkages. Open Economies Review, 11; 135-148.

Lacheheb, M. L., \& Sirag, A. (2019). Oil price and inflation in Algeria: a nonlinear ARDL approach. The Quarterly Review of Economics and Finance. DOI:/10.1016/j.qref.2018.12.003.

Lee, S., \& Kim, Y. M. (2018). Inflation expectation, monetary policy credibility and exchange rates. Finance Research Letters.

MacDonald, R. (1987). The demand for international reserves in a regime of floating exchange rates. Economics Letters. 23; 189-192.

Mankiw, N. (2017). The Principle of Economics. Mc Graw Hill Education: New York.

Martinez, J. D. (1999). Mexico's balance of payments and exchange rates: A Cointegration Analysis. North American Journal of Economics and Finance, 10, 401 - 421.

Onis, Z., \& Ozmucur, S. (1990). Exchange rates, inflation and money supply in Turkey. Journal of Development Economics, 32, 133 - 154.

Pal, D., \& Mitra, S. M. (2019). Asymmetric oil price transmission to the purchasing power of the U.S. dollar: A multiple threshold NARDL modelling approach. Resources Policy. doi:10.1016/j.resourpol.2019.101508.

Pesaran, M. H., Shin, Y., \& Smith, R.J. (2001). Bounds testing approaches to the analysis of level relationships. Journal of Applied Econometrics, 16(3). 289-326.

Seghezza, E., Morelli, P., \& Giovanni, P. (2017). Reserve accumulation and exchange rate policy in China: The authoritarian elite's aim of political survival. European Journal of Political Economy. 46; 40-51. 
Seghezza, E., Morelli, P., and Pittaluga, G. B. (2017). Reserve accumulation and exchange rate policy in China: The authoritarian elite's aim of political survival. European Journal of Political Economy. 47; 163-174.

Sek, S. K. (2017). Impact of oil price changes on domestic price inflation at disaggregated levels: Evidence from linear and nonlinear ARDL modeling. Energy. 103, 204-217.

Shin, Y., Yu, B., \& Greenwood-Nimmo, M. (2014). Modelling asymmetric cointegration and dynamic multipliers in a nonlinear ARDL framework. The Festschrift in Honor of Peter Schmidt.: Econometric Methods and Applications. ed. William Horrace; Robin Sickles. New York : Springer, 2014. pp. 281-314.

Yuravlivker, D. E. (1987). Political shocks, international reserves and the real exchange rateThe Argentine case. Journal of International Money and Finance. 6; 401-417. 